\title{
Spatial Relationship between Adult Malaria Vector Abundance and Environmental Factors in Western Kenya Highlands
}

\author{
Guofa Zhou,* Stephen Munga, Noboru Minakawa, Andrew K. Githeko, and Guiyun Yan \\ Program in Public Health, College of Health Sciences, University of California, Irvine, California; Centre for Vector Biology and \\ Control Research, Kenya Medical Research Institute, Kisumu, Kenya; Institute of Tropical Medicine, Nagasaki University, \\ Nagasaki, Japan
}

\begin{abstract}
Information on the spatial relationships between disease vectors and environmental factors is fundamental to vector-borne disease control. Although it is well known that mosquito abundance is associated with the amount of rainfall and thus the number of larval breeding sites, the spatial relationship between larval habitat availability and adult mosquito abundance is not clear. We investigated the impact of environmental heterogeneity and larval habitats on the spatial distribution of Anopheles gambiae s. s. and An. funestus adult mosquitoes, the most important malaria vectors in the highlands of western Kenya. Mosquito sampling was conducted in May, August, and November 2002, and February 2003. Geographic information system layers of larval habitats, land use type, human population distribution, house structure, and hydrologic schemes were overlaid with adult mosquito abundance. Correlography was used to determine the spatial autocorrelation in adult mosquito abundance among houses and the cross-correlation between adult mosquito abundance and environmental factors. Getis' $G_{i}^{*}(d)$ index was used to define focal adult mosquito abundance clusters. We found a significant autocorrelation in the vector population and a significant cross-correlation between the vector population and larval habitat availability. The threshold distances of both autocorrelation and cross-correlation were significantly varied among seasons. Focal clustering analysis revealed that the adult vector population was concentrated along the Yala River Valley where most larval habitats were found. Regression analysis found that distance of a house to the Yala River, age of the house, elevation, house structure, and tree canopy coverage significantly affected adult mosquito abundance. Our results suggest that vector control targeted at malaria transmission hotspots and supplemented by larval control may be an effective approach for epidemic malaria control in the western Kenya highlands.
\end{abstract}

\section{INTRODUCTION}

Information on the spatial distribution and temporal dynamics of anopheline mosquitoes and how environmental factors affect the spatial-temporal dynamics of vectors is crucial to the development of effective malaria control measures. It is well known that malaria infections are not distributed homogenously, with some areas or some households within the same area showing higher malaria incidence than others. ${ }^{1-5}$ Distance to larval habitats was found to be associated with vector abundance in a house and therefore, with malaria risks. ${ }^{6-8}$ However, other factors also contribute to the spatial heterogeneity of transmission intensity in a community, including land use and land cover, topography, house building materials and structures, the level of household protection measures against mosquitoes. ${ }^{6,9-15}$ How these factors influence the distribution and abundance of African malaria vectors is unknown. An important task of disease vector ecologic research is to determine the relative contribution of these environmental factors on the spatial heterogeneity of vector distribution.

The objective of the present study is to determine the spatial distribution of Anopheles populations and the spatial association between adult vector abundance and environmental factors in the western Kenya highlands. Since the late 1980s, a series of malaria outbreaks has occurred in the western Kenya highlands where malaria incidence used to be low. ${ }^{16-19}$ Epidemics of malaria have been reported in the highlands of more than 10 countries in Africa. ${ }^{10,18}$ The causes of epidemic malaria in the highlands are being debated. ${ }^{17,20-25}$ The highlands are characterized by complex topography consisting of valleys, hills and plateaus, and a mosaic of land use and land

* Address correspondence to Guofa Zhou, Program in Public Health, College of Health Sciences, University of California, 3501 Hewitt Hall, Irvine, CA 92697. E-mail: zhoug@uci.edu cover. ${ }^{13}$ Over the past four decades, the western Kenya highlands have been experiencing dramatic land use changes such as deforestation and swamp cultivation. ${ }^{26,27}$ This land use change has significantly influenced vector larval habitat availability and productivity and adult mosquito life history traits and distribution. ${ }^{10,12-15,28,29}$ The complexity of topography and landscape in the highlands contributes to the spatial heterogeneity of vector abundance and malaria transmission intensity. Anopheles gambiae s. s. and An. funestus are the only malaria vector mosquito species in the highlands of western Kenya. ${ }^{30}$ Anopheles gambiae s. s. shows a strong preference for temporary breeding sites, as opposed to the permanent bodies of water where most An. funestus breeding sites have been found. Anopheline larval habitats were aggregated in valley bottoms in both the rainy and dry seasons because of hilly topography. ${ }^{13,30}$ The spatial relationship between larval habitat availability, environmental factors, and adult mosquito abundance has not been established. Therefore, we examined the spatial distribution of adult vector abundance and the seasonal change in the spatial distribution pattern, the spatial correlation between adult mosquito distribution and larval breeding site availability, and the effects of spatial and non-spatial environmental factors on the spatial distribution of the malaria vector population.

\section{MATERIALS AND METHODS}

Study area. The study was conducted in the village of Iguhu $\left(34^{\circ} 45^{\prime} \mathrm{E}, 0^{\circ} 10^{\prime} \mathrm{N}, 1,430-1,580\right.$ meters above sea level), Kakamega District, western Kenya. Typically, the region has two rainy seasons (April-May and October-November) and two dry seasons (January-February and July-August). The $4 \times 4$ $\mathrm{km}^{2}$ study area consists of approximately 2,500 households and a human population of approximately 11,000. According to the observation from Kakamega meteorologic station (approximately $20 \mathrm{~km}$ from the study site), the 1960-1999 aver- 
age annual rainfall was $1,977 \mathrm{~mm}$, mean minimum temperature was $13.8^{\circ} \mathrm{C}$, and mean maximum temperature was $28.0^{\circ} \mathrm{C}$. The study area covers a portion of the Yala River valley (Figure 1). The study area includes a mosaic of land use types. $^{31}$ The hills are mostly maize land dotted by patches of tea plantation, and several swamps are located along the Yala River valley. A natural forest is located in the east side of the study area, constituting approximately $15 \%$ of the total area. The annual malaria transmission intensity in the study area in 2003-2004 was estimated to be 16.6 infectious bites per person per year, ${ }^{32}$ and thus the area can be classified as mesoendemic in a highland-fringe region. Malaria prevalence varied from $21 \%$ to $57 \%$ during $2002-2003$, and children 1-9 years of age consistently exhibited the highest prevalence (47.0\%) and adults $>19$ years of age showed the lowest prevalence $(9.5 \%) .^{5}$
Mosquito sampling. Adult mosquito samplings were conducted in an area of $3 \times 3 \mathrm{~km}^{2}$ using the indoor pyrethrum spray collection method in the long rainy season (May 8-15, $2002 ; \mathrm{n}=100$ ), ${ }^{33}$ and cool dry season (July 18-August 14 , 2002; $\mathrm{n}=80)$, and in an area of $4 \times 4 \mathrm{~km}^{2}$ in the short rainy season (November 11-December 3, 2002; $\mathrm{n}=300$ ) and the hot dry season (February 13-28, 2003; $n=200$ ). The houses for vector abundance surveillance were chosen randomly, and the global positioning system (GPS) coordinates were recorded using differential GPS. Anopheline mosquito abundance was measured as the number of female mosquitoes per house; only female mosquito abundance was analyzed because they are responsible for malaria transmission and have a strong endophilic resting behavior. Mosquito aquatic habitats in the study area were thoroughly searched for the
A

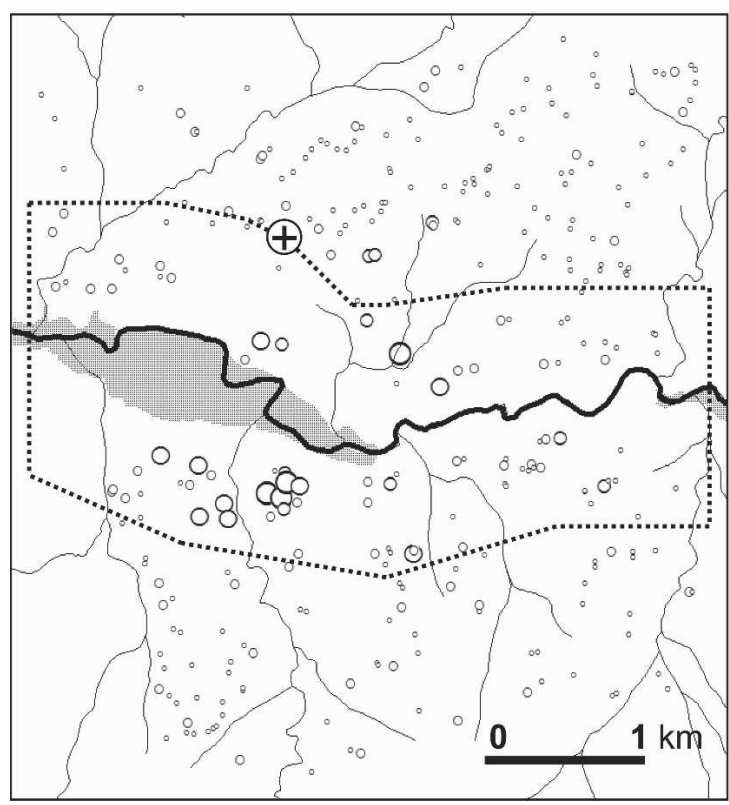

B

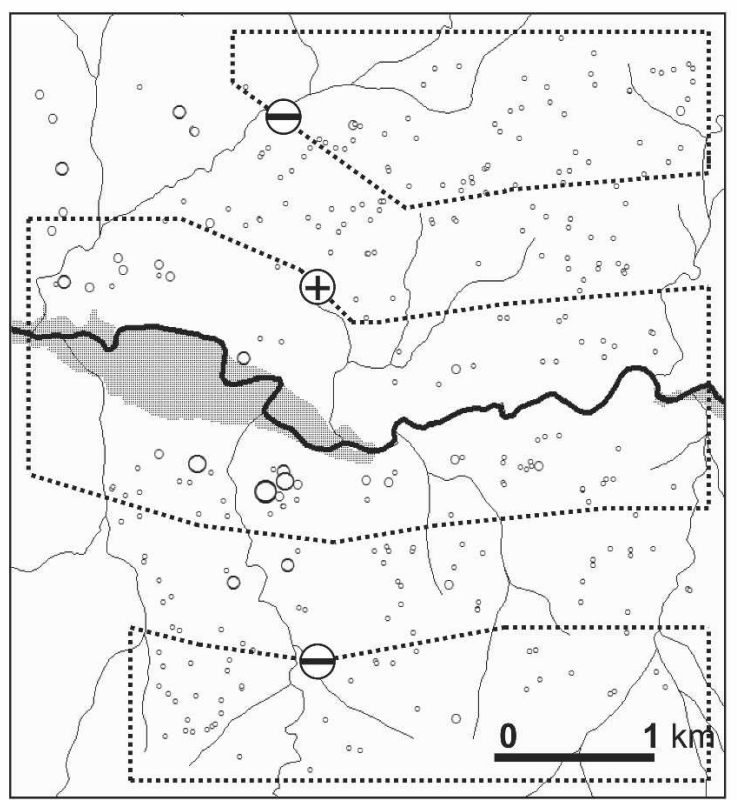

Abundance

- 0

- $1-5$

○ $6-10$

O $11-25$

$0>25$

1- Stream

Yala river

Swamp

Breeding site

Negative

Positive

C

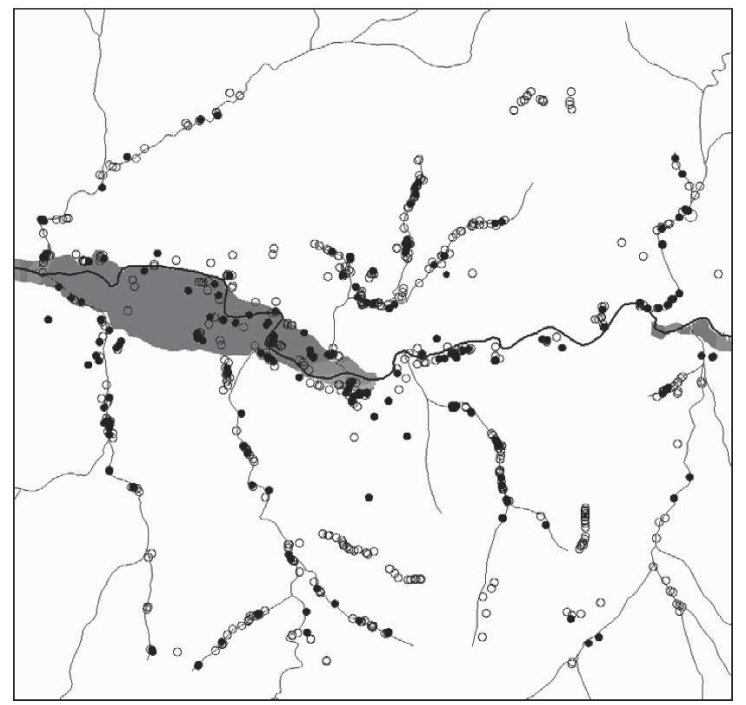

FIGURE 1. Spatial distribution of Anopheles gambiae s. s. (A) and An. funestus (B) abundance and anopheline larval breeding sites (C) in Iguhu, Kakamega District, western Kenya in November 2002. The area marked with the + symbol represents high abundance cluster, and the area marked with the - symbol is a low abundance cluster. 
presence of anopheline larvae 7-10 days before adult sampling by careful ground survey. Anopheline larvae were collected from positive habitats and identified to species based on the morphologic keys. ${ }^{34}$

Land use and land cover characterization. Because land use and land cover has a strong effect on the development and survivorship of $A n$. gambiae s. s. larvae in the western Kenya highlands, land use and land cover types in the study area were mapped based on a multispectral (blue, green, red, and infrared) Ikonos image with one-meter ground resolution (http://www.spaceimaging.com/products/imagery.htm). The image was geometrically and radiometrically corrected to account for topographic distortions and atmospheric effects with ground truthing in 100 randomly selected points. ${ }^{35}$ Land covers were classified as farmland, pastureland, forest, and natural swamp. Farmlands were characterized by the presence of any agricultural crops and bare ground that had been prepared for planting crops. Pastures were grasslands used for grazing. An area with a mixture of grass and shrubs was also classified as pasture. Forests were defined as areas with a tree canopy cover greater than $70 \%$. Natural swamps were characterized by the presence of emergent aquatic plants, and this was the category with the least modification by anthropogenic activities. The detailed procedure on land use and land cover characterization was described by Mushinzimana and others. $^{31}$

Household and house structure parameters. A total of 871 households were randomly selected and surveyed to obtain information on parameters that may be related to malaria transmission, including 1) house location, i.e., latitude and longitude, elevation and slope type (hilltop, middle of hill, or valley bottom); 2) house structures, i.e., roof type (thatch, tile or iron sheet), wall type (mud or brick), house size (floor area size in $\mathrm{m}^{2}$ ), window type (closed or open), presence or absence of eaves, and the year that the house was built; and 3) the number of sleepers in each house. Because of the small number of houses with tile roofs $(n=3)$, mosquito samples from these houses were excluded from analysis.

Spatial data analysis. Cross-correlation analysis was used to determine the spatial correlation between positive larval habitats and adult mosquito density. Underlying assumption of this analysis is that, on average, houses close to larval habitats will have more adult mosquitoes than those farther away. The cross-correlation statistic, $\rho_{u v}(h)$, is analogous to the Person correlation coefficient between variables at points separated by a distance $h .^{36}$ The $h-\rho_{u v}(h)$ graph, or crosscorrelography, is used to quantify the spatial association. If two variables are positively correlated spatially, $\rho_{\mathrm{uv}}(h)$ will be positive when inter-house distance $h$ is small, and then decrease toward zero with increasing $h$. If two variables are negatively correlated spatially, $\rho_{\mathrm{uv}}(h)$ will be negative with small $h$, and then approach zero with increasing $h$. The distance $h_{\mathrm{o}}$, at which $\rho_{\mathrm{uv}}(h)=0$, indicates the threshold distance beyond which spatial correlation between the two variables is not statistically significant. Because of the small sample size of houses located within 200 meters of any positive larval habitats, the cross-correlation analysis excluded the houses within 200 meters distance from larval habitats.

The parameter $\rho_{\mathrm{uv}}(h)$ also measures spatial autocorrelation if $u$ and $v$ are the same. In this case, $\rho_{\mathrm{uv}}(h)$ is simplified as $\rho(h)$. In a typical case of aggregated distribution, $\rho(h)$ is close to 1 when $h$ is small, but it decreases and sometimes becomes negative as $h$ increases. Parameter $\rho(h)$ is similar to Moran's $I$ index, and has been widely used by ecologists. ${ }^{37}$ If mosquito abundance in neighboring houses is correlated, then the appropriate neighborhood size is the maximum distance at which the abundance is correlated. Household and house structure variables were subjected to autocorrelation and cross-correlation analysis.

Significant neighborhood correlation detected by correlography is also an indication of global clustering, but it does not provide information on local or focal clustering. Getis' local statistic $G_{\mathrm{i}}^{*}(d)$ tests local clustering. ${ }^{38-40}$ By comparing local estimates of spatial autocorrelation with global averages, the $G_{\mathrm{i}}^{*}(d)$ statistic identifies hotspots in the spatial data. In this way, it can be determined whether specific houses are located in transmission hotspots. Because most larval habitats were clustered in the valley bottom along the Yala River, ${ }^{31}$ we used $G_{i}^{*}(d)$ statistic to determine whether adult mosquitoes were also clustered along the Yala River.

We used multiple regression analysis to determine the effects of environmental factors on adult mosquito abundance. Because regression analysis is biased when spatial autocorrelation is present, we removed the spatial association in these variables prior to the regression analysis using Getis' spatial screening method. ${ }^{41}$ If a significant $G_{\mathrm{i}}^{*}(d)$ was found, we used Getis' spatial filter method to separate the spatial component from the non-spatial component for both dependent variables (adult mosquito abundance) and independent variables. The stepwise multiple regression analysis was used to select the household and house structure variables and land use factors that significantly affect adult mosquito abundance. Topographic variables were also included in the regression analysis, including distance to the nearest larval habitats, the nearest distance to the Yala River and elevation. Anopheles gambiae s. s. and $A n$. funestus were analyzed separately. For presentation simplicity, the effects of the factors significantly associated with malaria vector abundance were quantified by relative risk index using pooled data from the four samplings. The $95 \%$ confidence interval of relative risk index was calculated. Quantitative variables such as distance to the Yala River, house age, number of sleepers, and elevation were categorized into several classes based on the sample size distribution of the variables.

\section{RESULTS}

Spatial autocorrelation and local clustering analyses of adult mosquito abundance. Anopheles gambiae s. s. and An. funestus were the only malaria vector species in the study site. Anopheles gambiae s. s. was the predominant malaria vector species in the study area, constituting 94\%, 61\%, 85\%, and $89 \%$ of the vector populations collected in the months of May, August, and November 2002, and February 2003, respectively. Higher abundances of An. gambiae s. s. and $A n$. funestus adults were observed in houses near the valley bottom along the Yala River (Figure 1). Spatial autocorrelation analysis found that mosquito abundances in neighboring houses were correlated, but the distance within which spatial autocorrelation remained significant (or neighborhood size) varied among seasons (Figure 2). For example, the neighborhood size was 250-350 meters in May and August, 2002, and 1,000-1,250 meters in November 2002 and February 2003 for An. gambiae s. s. For An. funestus, the neighborhood size was 


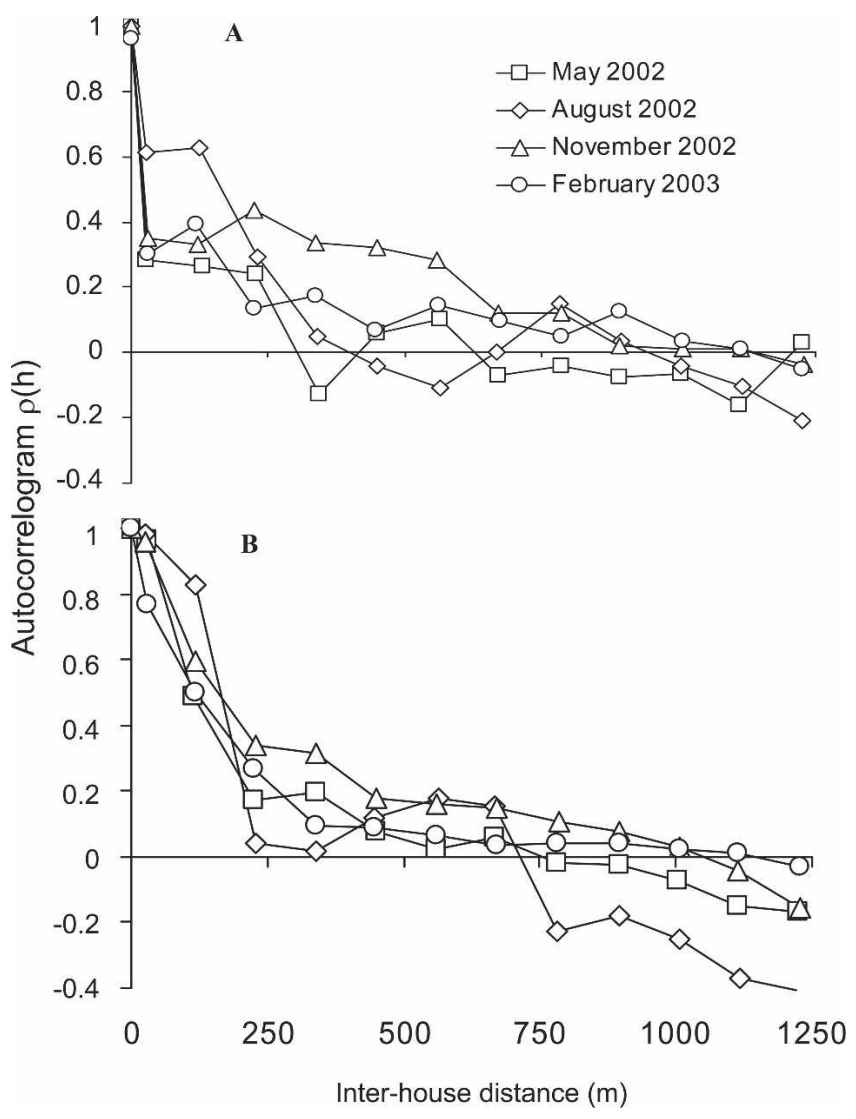

FIgURE 2. Autocorrelation of Anopheles gambiae s. s. (A) and An. funestus (B) abundance against inter-house distance.

700-750 meters in May and August, 2002, and 1,000-1,100 meters in November 2002 and February 2003. The increased neighborhood size in the last two surveys was due to the fact that study area size was increased from $9 \mathrm{~km}^{2}$ to $16 \mathrm{~km}^{2}$.

Results of Getis' $G_{i}^{*}(d)$ statistic indicated that highabundance clusters were located in the valley bottom along the Yala River, and low-abundance clusters were located on the hilltops of the study area (Figure 1). This pattern was consistent for the four sampling seasons. The location of the high-abundance cluster was typically within 400-450 meters of the Yala River. The low-abundance clusters were located, on average, $\geq 800$ meters from the Yala River. These focal clusters likely resulted from the aggregated distribution of larval habitats and the limited dispersal ability of adult mosquitoes. ${ }^{31}$

Spatial relationship between adult mosquito abundance and larval habitat availability. We found a total of 755, 190, 786, and 658 potential aquatic habitats in May, August, and November 2002, and February 2003, respectively. Among these sites, $271(35.9 \%), 47$ (24.7\%), $224(28.5 \%)$, and 312 $(47.4 \%)$ habitats contained anopheline larvae for the respective sampling seasons. More than $80 \%$ of anopheline-positive habitats were located within 100 meters of the nearest streams.

Cross-correlation analysis found that adult mosquito abundance was significantly correlated with larval habitat availability up to a distance of 550-600 meters in the May and August 2002 surveys, and 1,000-1,100 meters in the November 2002 and February 2003 surveys, and this pattern was consistent in both An. gambiae s. s. and An. funestus (Figure 3). The threshold distance within which spatial correlation between larval habitat availability and adult abundance remains significant is consistent with the dispersal ability of adult mosquitoes. ${ }^{42,43}$

Multiple regression of adult mosquito abundance. We identified seven variables that significantly influence adult mosquito abundance: the distance to the Yala River, the year the house was built, elevation where the house is located, wall type, window type, roof type, and tree canopy coverage over the roof (Table 1). For example, houses near the Yala River showed a significantly higher anopheles mosquito abundance than those farther away from the river, and a significantly higher portion of houses in the river valley had anopheline mosquitoes. Similarly, houses located at the lower elevations $(\leq 1,470$ meters above sea level) had more than three-fold higher abundance of An. gambiae s. s. than houses located at higher elevations. Mosquito abundance was significantly lower in older houses, and was significantly higher in houses with mud walls and grass thatch roofs or in the deforested area (low roof canopy coverage) than in their respective counterparts. The effect of these variables on An. funestus abundance was similar to that on An. gambiae s. s., but $A n$. funestus abundance was much lower than An. gambiae s. s. (Table 1).

Overall, the spatial components explained $41 \%$ variance in mosquito abundance, and the non-spatial components accounted for only $18 \%$ variance. In all four sampling seasons, spatial components accounted for more variance in vector

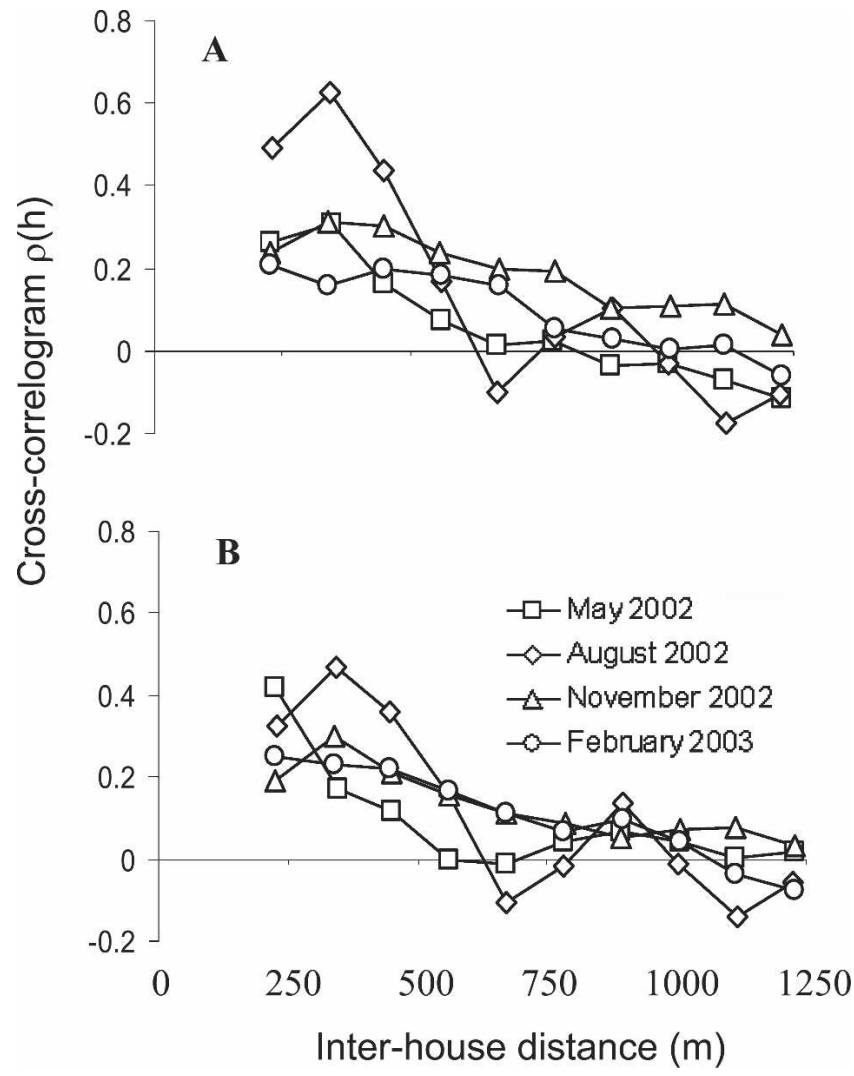

FIGURE 3. Cross-correlation between mosquito adult and larval habitats. A, Anopheles gambiae s. s. versus its larval habitats. B, An. funestus versus its larval habitats. 
TABLE 1

Results of multiple regression analyses for anopheline adult abundance, houses with anopheline female mosquitoes, and environmental factors in western Kenya highlands

\begin{tabular}{|c|c|c|c|c|}
\hline \multirow[b]{2}{*}{ Variable } & \multicolumn{2}{|c|}{ Abundance* ( $95 \%$ confidence interval) } & \multicolumn{2}{|c|}{ Odds ratio $\dagger$ ( $95 \%$ confidence interval) } \\
\hline & An. gambiae s. s. $\ddagger$ & An. funestus & An. gambiae s. s. & An. funestus \\
\hline \multicolumn{5}{|c|}{ Distance to Yala River, meters } \\
\hline$<500$ & $6.28(4.46,8.10) \mathrm{a}$ & $0.88(0.66,1.10) \mathrm{a}$ & $1.89(1.82,1.96)$ & $2.01(1.89,2.13)$ \\
\hline $500-999$ & $2.86(2.00,2.72) b$ & $0.30(0.13,0.47) \mathrm{b}$ & $1.42(1.36,1.47)$ & $1.54(1.41,1.68)$ \\
\hline$\geq 1,000$ & $1.09(0.59,1.59) \mathrm{c}$ & $0.17(0.07,0.27) b$ & 1 & 1 \\
\hline \multicolumn{5}{|c|}{ Year that the house was built } \\
\hline Before 1985 & $4.38(3.34,5.52) \mathrm{a}$ & $0.58(0.43,0.73)$ a & $1.39(1.34,1.44)$ & $1.38(1.29,1.46)$ \\
\hline After 1986 & $1.83(0.97,2.69) \mathrm{b}$ & $0.25(0.15,0.35) b$ & 1 & 1 \\
\hline \multicolumn{5}{|c|}{ Elevation (meters above sea level) } \\
\hline$\leq 1,470$ & $5.14(3.88,6.40) \mathrm{a}$ & $0.68(0.51,0.85) \mathrm{a}$ & $1.54(1.50,1.58)$ & $2.03(1.91,2.15)$ \\
\hline$>1,470$ & $1.60(1.01,2.19) \mathrm{b}$ & $0.22(0.07,0.27) \mathrm{b}$ & 1 & 1 \\
\hline \multicolumn{5}{|l|}{ Wall type } \\
\hline Mud & $4.16(3.24,5.08) \mathrm{a}$ & $0.53(0.37,0.65) \mathrm{a}$ & $1.34(1.29,1.40)$ & $1.87(1.70,2.04)$ \\
\hline Brick & $0.86(0.53,1.19) \mathrm{b}$ & $0.22(0.06,0.38) b$ & 1 & 1 \\
\hline \multicolumn{5}{|l|}{ Window type } \\
\hline No screen & $4.15(3.95,5.35) \mathrm{a}$ & $0.52(0.37,0.67) \mathrm{a}$ & $1.04(1.01,1.07)$ & $1.14(1.09,1.20)$ \\
\hline Screened & $2.92(2.08,3.76) b$ & $0.44(0.29,0.59)$ a & 1 & 1 \\
\hline \multicolumn{5}{|l|}{ Roof type§ } \\
\hline Grass thatch & $4.26(3.15,5.37) \mathrm{a}$ & $0.39(0.27,0.51) \mathrm{a}$ & $1.15(1.12,1.19)$ & $0.75(0.71,0.79)$ \\
\hline Iron sheet & $2.00(1.33,2.67) b$ & $0.61(0.39,0.83) b$ & 1 & 1 \\
\hline \multicolumn{5}{|c|}{ Tree canopy coverage (\%) } \\
\hline$\leq 10$ & $3.99(3.04,4.94) \mathrm{a}$ & $0.53(0.40,0.66)$ a & $1.36(1.31,1.41)$ & $1.30(1.21,1.39)$ \\
\hline$>10$ & $2.23(1.40,3.06) b$ & $0.31(0.16,0.46) b$ & 1 & 1 \\
\hline
\end{tabular}

abundance than the non-spatial component with one exception of An. funestus in the May 2002 sampling.

\section{DISCUSSION}

In this study, spatial autocorrelation analysis was used to determine the spatial distribution patterns of malaria vectors in the western Kenya highlands where frequent epidemic malaria has been reported in the past two decades. Positive spatial autocorrelation in mosquito abundance indicates mosquito distribution was spatially aggregated. Both global and focal clustering of adult mosquitoes can be attributed to the aggregated distribution of larval habitats in the valley bottom. ${ }^{13,31}$ The western Kenya highlands are characterized by hilly topography. Stagnant bodies of water cannot often accumulate in hills sufficiently long to render mosquito larvae capable of successfully completing the life cycle. Thus, the valley was the primary area where suitable larval habitats were formed. This is especially true during the dry season where larval habitats were more limited. As expected, we found a high abundance of mosquitoes clustering within an area of 400-500 meters from the Yala River. The cluster size may be explained by the topography and the limited adult mosquito dispersal ability. ${ }^{42}$ This result is consistent with other studies, which showed that homes close to breeding sites exhibited higher mosquito abundance. $^{6,8}$

We found substantial spatial-temporal variations in mosquito abundance. The temporal change in mosquito abundance is mainly caused by rainfall changes. Anophelesa gambiae s. s. adults were more abundant during the rainy season than during the dry season, which is consistent with the finding that the number of larval habitats was substantially higher in the rainy season than in the dry season. The lower abundance of An. funestus adults than An. gambiae s. s. was caused by the lack of suitable, long-lasting larval habitats for $A n$. funestus because $A n$. funestus larvae normally take three weeks to develop into adults, and An. gambiae s. s. larvae require approximately 10 days in sun-lit habitats. ${ }^{15}$ The spatial variation in $A n$. gambiae s. s. abundance is attributed to environmental heterogeneity, house location, and age and type of structure. Mosquito larval habitats are normally clustered along the river valleys or streams in hilly areas of the western Kenya highlands. Where a house is located has an important impact in malaria risk. In this study, we found that houses within the 500-meter range of the Yala River showed 5-6-fold higher mosquito abundance than houses uphill and more than 1,000 meters from the Yala River. Ribeiro and others suggested that the mosquito-breeding habitats along an irrigation canal in their study site was the major factor causing the aggregated distribution of An. gambiae s. s. ${ }^{44}$ Other studies also found that people who resided near mosquito breeding sites had a higher malaria risk. ${ }^{6,8,45-48}$ Interestingly, we found that mosquito abundance in older houses was 2-3-fold less than that in the newer houses. Prior to the year 1990 , more than $70 \%$ (322 of 443) of houses were located more than 200 meters from the Yala River, whereas almost half (209 of 428) of houses built after 1990 were located within 200 meters of the Yala River. More residents had to settle in areas near the river valley, where anopheline larval habitats are more abundant and malaria transmission intensity has been higher in recent years, because of the rapid increase in human population. Thus, through its effects on the spatial distribution of larval habitats and human settlement patterns, topography can have a significant impact on human malaria transmission. 
It is not surprising that types of house structures, such as walls and roofs, and whether the windows have screens significantly affect mosquito abundance inside a house. In our study site, the walls in approximately two-thirds of the houses were made of wood sticks pasted with mud. More than $90 \%$ of the mud-walled houses had windows without screens and more than $70 \%$ of the mud-walled houses had thatch grass roofs. Windows without screens enable mosquitoes to enter the houses easily, and thatch-grass roofs and mud walls provide benign resting sites for blood fed mosquitoes. Conversely, houses with brick walls are usually installed with screened windows and iron sheet roofs. Clearly, such types of houses protect residents from being bitten by malariacarrying mosquitoes. However, the higher construction costs of brick houses with corrugated iron-sheet roofs and screened windows limit the wide use of these construction materials by local residents.

We found that tree canopy coverage exhibited a significant effect on mosquito abundance in houses. Tree canopy reduces the water temperature of larval habitats surrounding the houses because canopy cover reduces the amount of solar radiation reaching the larval habitats. In the same study area, we found that the annual average water temperature was $2.4^{\circ} \mathrm{C}$ lower in natural habitats located in the forested area than in farmland. ${ }^{15}$ In addition, the algal contents, one major food source of An. gambiae s. s. larvae, was considerably lower in larval habitats in the forest than in the farmland. Larvae-to-adult survivorship was only $2 \%$ for habitats in forested areas, whereas the larval survivorship exceeded $49 \%$ in habitats located in the farmland. Moreover, the larvae from forested habitats took a much longer time to develop into adults than those from farmland habitats (three weeks versus two weeks). ${ }^{15}$ Thus, land cover affects larval survivorship and adult productivity through its effects on water temperature and nutrients in the aquatic habitats. Air temperature inside a house was also affected by tree canopy. Houses located in deforested areas showed a $1.2-1.8^{\circ} \mathrm{C}$ higher average temperature than those in the forested area. ${ }^{28}$ As a consequence of increased air temperature, the duration of gonotrophic cycles was shortened by approximately 1.5 days, implying increased daily biting frequency. ${ }^{29}$ In addition, mosquitoes placed in houses in the deforested area showed a 64.8-79.5\% higher fecundity than those in houses located in the forested area. Thus, increased anopheline mosquito abundance in areas with low canopy coverage was a result of increased larval survivorship and increased fecundity in the adult mosquito population. We estimated that female mosquitoes in the deforested area showed a $38.5-40.6 \%$ increase in net reproductive rate than those in the forested area. ${ }^{29}$

Our findings have implications on malaria vector control in the western Kenya highlands. The aggregated distribution of anopheline larval habitats and significant spatial correlation between larval habitats and adult mosquito abundance suggests that larval control may be a valuable method for reducing malaria transmission intensity. Larval control could be conducted through elimination of breeding sites or through the use of biologic insecticides such as Bacillus thuringiensis var. israelensis and B. sphaericus that specifically kill mosquito larvae. Larval control may be used as supplemental methods to insecticide-impregnated bed nets or indoorresidual sprays that target adult mosquitoes. Because larval habitats in the highlands were clustered along river valleys and streams, their locations can be predicted by remote sensing techniques and topographic features of the targeted area. ${ }^{31}$ Because adult mosquitoes were also aggregated along river valleys, larval control in combination with adult control of anopheline mosquitoes may be a highly cost-effective method for control of epidemic malaria in the western Kenya highlands.

Received December 29, 2006. Accepted for publication March 30, 2007.

Acknowledgments: We thank Maurice Okonji, Stephen Ajuma, Peter A. Lutiali, Wilberforce Miheso, and Amos Wabwile for technical assistance, and two anonymous reviewers for valuable comments and suggestions. This paper is published with the permission of the Director of the Kenya Medical Research Institute.

Financial support: This work was supported by National Institutes of Health grants R01 AI 50243 and D43 TW01505.

Authors' addresses: Guofa Zhou and Guiyun Yan, Program in Public Health, College of Health Sciences, University of California, Irvine, CA 92697, E-mails: zhoug@uci.edu and guiyuny@uci.edu. Stephen Munga and Andrew K. Githeko, Kenya Medical Research Institute, Kisumu, Kenya, E-mails: smunga@kisian.mimcom.net and agitheko@ kisian.mimcom.net. Noboru Minakawa, Faculty of Medicine, Saga University, 5-1-1 Nabeshima, Saga 849-8501, Japan, E-mail: minakawa@ post.saga-med.ac.jp.

Reprint requests: Guiyun Yan, Program in Public Health, College of Health Sciences, University of California, Irvine, CA 92697.

\section{REFERENCES}

1. Mendis C, Gamage-Mendis AC, de Zoysa AP, Abhayawardena TA, Carter R, Herath PRJ, Mendis KN, 1990. Characteristics of malaria transmission in Kataragama, Sri Lanka: a focus for immmuno-epidemiological studies. Am J Trop Med Hyg 42: 298-308.

2. Gamage-Mendis AC, Carter R, Mendis C, de Zoysa AP, Herath PR, Mendis KN, 1991. Clustering of malaria infections within an endemic population: risk of malaria associated with house construction type. Am J Trop Med Hyg 45: 77-85.

3. Carter R, Mendis KN, Roberts D, 2000. Spatial targeting of interventions against malaria. Bull World Health Organ 78: 1401-1411.

4. Brooker S, Clarke S, Njagi JK, Polack S, Mugo S, Estambale B, Muchiri E, Magnussen E, Cox J, 2004. Spatial clustering of malaria and associated risk factors during an epidemic in a highland area of western Kenya. Trop Med Int Health 9: 757766.

5. Munyekenye OG, Githeko AK, Zhou G, Mushinzimana E, Minakawa N, Yan G, 2005. Plasmodium falciparum spatial analysis, western Kenya highlands. Emerg Infect Dis 10: 15711577.

6. van der Hoek W, Konradsen F, Dijkstra DS, Amerasinghe PH, Amerasinghe FP, 1998. Risk factors for malaria: a microepidemiological study in a village in Sri Lanka. Trans $R$ Soc Trop Med Hyg 92: 265-269.

7. Minakawa N, Pamela S, Yan G, 2002. Influence of host and larval habitat distribution on the abundance of African malaria vectors in western Kenya. Am J Trop Med Hyg 67: 32-38.

8. Cano J, Descalzo MA, Moreno M, Chen Z, Nzambo S, Bobuakasi L, Buatiche JN, Ondo M, Micha F, Benito A, 2006. Spatial variability in the density, distribution and vectorial capacity of anopheline species in a high transmission village (Equatorial Guinea). Malaria J 5: 21.

9. Khaemba BM, Mutani A, Bett MK, 1994. Studies of anopheline mosquitoes transmitting malaria in a newly developed highland urban area: a case study of Moi University and its environs. East Afr Med J 71: 159-164.

10. Mouchet J, Manguin S, Sircoulon K, Lavnevale S, Faye S, Onapa AW, Carnevale P, Julvez J, Fontenille D, 1998. Evolution of malaria in Africa for the past 40 years: impact of climatic and human factors. J Am Mosq Control Assoc 14: 121-130. 
11. Shililu JI, Maier WA, Seitz HM, Orago AS, 1998. Seasonal density, sporozoite rates and entomological inoculation rates of Anopheles gambiae and Anopheles funestus in a high-altitude sugarcane growing zone in western Kenya. Trop Med Int Health 3: 706-710.

12. Lindblade KA, Walker ED, Onapa AW, Katungu J, Wilson ML, 2000. Land-use change alters malaria transmission parameters by modifying temperature in a highland area of Uganda. Trop Med Int Health 5: 263-274.

13. Minakawa N, Munga S, Atieli F, Mushinzimana E, Zhou G, Gethiko A, Yan G, 2005. Spatial distribution of anopheline larval habitats in western Kenya highlands: Effects of land cover types and topography. Am J Trop Med Hyg 73: 157-165.

14. Minakawa N, Omukunda E, Zhou G, Githeko AK, Yan G, 2006. Malaria vector productivity in relation to the highland environment in Kenya. Am J Trop Med Hyg 75: 448-453.

15. Munga S, Minakawa N, Zhou G, Mushinzimana E, Barrack OJ, Githeko AK, Yan G, 2006. Association between landcover and production of malaria vectors in the western Kenyan highland. Am J Trop Med Hyg 74: 69-75.

16. Lindsay SW, Martens WJ, 1998. Malaria in the African highlands: past, present and future. Bull World Health Organ 76: 33-45.

17. Malakooti MA, Biomndo K, Shanks GD, 1998. Reemergnece of epidemic malaria in the highlands of western Kenya. Emerg Infect Dis 4: 671-676.

18. Cox J, Craig M, le Sueur D, Sharp B, 1999. Mapping Malaria Risk in the Highlands of Africa. MARA/ARMA Technical Report. Durban, South Africa: MARA/ARMA.

19. Githeko AK, Ndegwa W, 2001. Predicting malaria epidemics in the Kenyan highlands using climate data: a tool for decision makers. Glob Change Hum Health 2: 45-63.

20. Hay SI, Cox J, Rogers DJ, Randolph SE, Stern DI, Shanks GD, Myers MF, Snow RW, 2002. Climate change and the resurgence of malaria in the East African highlands. Nature 415: 905-909.

21. Shanks GD, Biomndo K, Hay HI, Snow RW, 2000. Changing patterns of clinical malaria since 1965 among a tea estate population located in the Kenyan highlands. Trans $R$ Soc Trop Med Hyg 94: 253-255.

22. Shanks GD, Biomndo K, Maguire J, 2004. Travel as a risk factor for malaria requiring hospitalization on a highland tea plantation in western Kenya. J Travel Med 11: 354-357.

23. Shanks GD, Hay SI, Omumbo JA, Snow RW, 2005. Malaria in Kenya's western highlands. Emerg Infect Dis 11: 1425-1432.

24. Zhou G, Minakawa N, Githeko A, Yan G, 2004. Association between climate variability and malaria epidemics in the East African highlands. Proc Natl Acad Sci U S A 101: 2375-2380.

25. Pascual M, Ahumada JA, Chaves F, Rodo X, Bouma M, 2006. Malaria resurgence in the east African highlands: temperature trends revisited. Proc Natl Acad Sci U S A 103: 5829-5834.

26. Round-Turner D, 1994. Kakamega Forest, the Official Guide 1994. Nairobi, Kenya: Kenya Indigenous Forest Conservation Programme.

27. Food and Agriculture Organization, 2005. Global Forest Resources Assessment 2005: Progress towards Sustainable Forest Management. Rome: Food and Agricultural Organization. Forestry paper 147

28. Afrane YA, Zhou G, Lawson BW, Githeko AK, Yan G, 2006. Effects of microclimatic changes due to deforestation on the survivorship and reproductive fitness of Anopheles gambiae in western Kenya highlands. Am J Trop Med Hyg 74: 772-778.

29. Afrane YA, Lawson BW, Githeko AK, Yan G, 2005. Effects of microclimatic changes caused by land use and land cover on duration of gonotrophic cycles of Anopheles gambiae (Diptera: Culicidae) in western Kenya highlands. J Med Entomol 42: 974-980.
30. Minakawa N, Sonye G, Mogi M, Githeko A, Yan G, 2002. The effects of climatic factors on the distribution and abundance of malaria vectors in Kenya. $J$ Med Entomol 39: 833-841.

31. Mushinzimana E, Munga S, Minakawa N, Li L, Feng C, Bian L, Kitron U, Schmidt C, Beck L, Zhou G, Githeko AK, Yan G, 2006. Comparison of three remote sensors for identification of anopheline mosquito larval habitats in western Kenya highlands. Malaria J 5: 13.

32. Ndenga B, Githeko A, Omukunda E, Munyekenye G, Atieli H, Wamai P, Mbogo C, Minakawa N, Zhou G, Yan G, 2006. Population dynamics of malaria vectors in western Kenya highlands. J Med Entomol 43: 200-206.

33. World Health Organization, 1975. Manual on Practical Entomology in Malaria. Part II. Methods and Techniques. No. 13. Geneva: World Health Organization.

34. Gillies MT, de Meillon B, 1968. The Anophelinae of Africa South of the Sahara. Johannesburg: The South African Institute for Medical Research.

35. Campbell J, 1996. Introduction to Remote Sensing. London: The Guildford Press

36. Liebhold AM, Rossi RE, Kemp WP, 1993. Geostatistics and geographic information systems in applied insect ecology. Annu Rev Entomol 38: 303-327.

37. Lichstein JW, Simons TR, Shriner SA, Franzreb KE, 2002. Spatial autocorrelation and autoregressive models in ecology. Ecol Monogr 72: 445-463.

38. Clennon JA, King $\mathrm{CH}$, Muchiri EM, Kariuki $\mathrm{CH}$, Ouma JH, Mungai P, Kitron U, 2004. Spatial patterns of urinary schistosomiasis infection in a highlay endemic area of coastal Kenya. Am J Trop Med Hyg 70: 443-448.

39. Getis A, Morrison AC, Gray K, Scott T, 2003. Characteristics of the spatial pattern of the Dengue vector, Aedes aegypti, in Iquitos, Peru. Am J Trop Med Hyg 69: 494-505.

40. Ord JK, Getis A, 1995. Local spatial autocorrelation statistics: distributional issues and an application. Geog Anal 27: 286306.

41. Getis A, 1990. Screening for spatial dependence in regression analysis. Pap Reg Sci Assoc 69: 69-81.

42. Costantini C, Li SG, Della-Torre A, Sagnon N, Coluzzi M, Taylor CE, 1996. Density, survival and dispersal of Anopheles gambiae complex mosquitoes in a west African Sudan savanna village. Med Vet Entomol 10: 203-219.

43. Toure YT, Dolo G, Petrarca V, Traore SF, Bouare M, Dao A, Carnahan J, Taylor CE, 1998. Mark-release-recapture experiments with Anopheles gambiae s.l. in Banambani Village, Mali, to determine population size and structure. Med Vet Entomol 12: 74-83.

44. Ribeiro JM, Seulu F, Abose T, Kidane G, Teklehaimanot A, 1996. Temporal and spatial distribution of anopheline mosquitoes in an Ethiopian village: implications for malaria control strategies. Bull World Health Organ 74: 299-305.

45. Gunawardena DM, Wickremasinghe AR, Muthuwatta L, 1998. Malaria risk factors in an endemic region of Sri Lanka, and the impact and cost implications of risk factor-based interventions. Am J Trop Med Hyg 58: 533-542.

46. Konradsen F, Amerasinghe P, van der Hoek W, Amerasinghe F, Perera D, Piyaratne M, 2003. Strong association between house characteristics and malaria vectors in Sri Lanka. Am J Trop Med Hyg 68: 177-181.

47. Lindsay SW, Jawara M, Paine K, Pinder M, Walraven GE, Emerson PM, 2003. Changes in house design reduce exposure to malaria mosquitoes. Trop Med Int Health 8: 512-517.

48. Yé Y, Hoshen M, Louis V, Séraphin S, Traoré I, Sauerborn R, 2006. Housing conditions and Plasmodium falciparum infection: protective effect of iron-sheet roofed houses. Malar J 5: 8. 